\title{
Die Verschuldung der afrikanischen Länder
}

L'endettement africain

\section{Eric Roethlisberger}

\section{(2) OpenEdition}

\section{Journals}

Édition électronique

URL : http://journals.openedition.org/sjep/1079

DOI : 10.4000/sjep.1079

ISSN : 1663-9677

\section{Éditeur}

Institut de hautes études internationales et du développement

\section{Édition imprimée}

Date de publication : 1 janvier 1986

Pagination : 135-141

ISSN : 1660-5926

\section{Référence électronique}

Eric Roethlisberger, «Die Verschuldung der afrikanischen Länder », Schweizerisches Jahrbuch für Entwicklungspolitik [En ligne], 6 | 1986, mis en ligne le 09 mars 2013, consulté le 08 septembre 2020 URL : http://journals.openedition.org/sjep/1079; DOI : https://doi.org/10.4000/sjep.1079

Ce document a été généré automatiquement le 8 septembre 2020

(c) The Graduate Institute 


\title{
Die Verschuldung der afrikanischen Länder
}

\author{
L'endettement africain
}

Eric Roethlisberger

\section{NOTE DE L'ÉDITEUR}

Zusammenfassung auf Deutsch. Volltext auf Französisch in Annuaire suisse de politique de développement: „L'endettement africain”, http://aspd.revues.org/1230.

\section{RÉSUMÉS}

Zwar ist die Auslandsschuld der afrikanischen Länder wesentlich geringer als diejenige Lateinamerikas, doch ist sie in den letzten zehn Jahren rasch angestiegen, und der Schuldendienst stellt heute für viele Länder eine schwere Belastung dar. Der Verfasser zählt die endogenen und exogenen Ursachen dieser Lage auf und legt die möglichen Mittel zu ihrer Behebung dar. Unter diesen haben die Umschuldungen und die Verstärkung der öffentlichen Entwicklungshilfe im Zusammenhang mit Afrika eine besonders wichtige Funktion. Im letzten Teil des Artikels wird die Rolle beschrieben, welche die Schweiz bei der Suche nach Lösungen des Schuldenproblems spielen kann, sowie die verschiedenen Instrumente, die der Regierung in diesem Bereich zur Verfügung stehen 